Revista Eletrônica em Gestão, Educação e Tecnologia Ambiental

Santa Maria, v. 20, n. 1, jan.-abr. 2016, p. 97-104

Revista do Centro de Ciências Naturais e Exatas - UFSM

ISSN : 22361170

\title{
Impactos ambientais dos resíduos sólidos no município de Pelotas/RS: Um olhar fotográfico
}

\author{
Environmental impacts of solid residues of Pelotas-Brazil: A photographic look \\ Beatriz Simões Valente, Eduardo Gonçalves Xavier, Júlia Martins Rodrigues, \\ Taís Helena Kivel
}

Universidade Federal de Pelotas

Resumo

O objetivo do estudo foi demonstrar os impactos ambientais dos resíduos sólidos no município de Pelotas/RS através de fotografias. A pesquisa caracteriza-se como um estudo de caso, tendo como base a percepção ambiental através do dispositivo do olhar dos investigadores sobre os impactos ambientais dos resíduos sólidos nas regionais do Fragata, Centro e Porto. As análises das imagens fotográficas demonstram que a disposição inadequada dos resíduos sólidos causa impactos ambientais no município de Pelotas e acarreta problemas sociais, ambientais, econômicos e administrativos. O gerenciamento dos resíduos sólidos é ineficiente e deve ser melhorado. A população deve realizar a segregação, o acondicionamento e a disposição correta dos resíduos domiciliares. A coleta seletiva e a reciclagem devem ser priorizadas para uma correta gestão dos resíduos sólidos da cidade. São necessários programas de educação ambiental que contemplem os diferentes âmbitos da sociedade para que seja alcançado o desenvolvimento sustentável do município e a melhoria da qualidade de vida da população.

Palavras-chave: contaminação urbana, gestão ambiental, lixo, reciclagem.

Abstract

The objective of this study was to demonstrate the environmental impacts of solid residues of Pelotas City-Brazil through photography. The research is characterized as a case study and its basis was the environmental perception through the dispositive of the look of the researchers on the environmental impact of the solid residues on the so called Fragata, Central and Porto regionals of the city. The analysis of the photographic images showed that the improper discharge of solid residues leads to environmental impacts in Pelotas and therefore causes social, environmental, economic and administrative issues. The management of the solid residues is inefficient and needs to be improved. The population must perform proper segregation, conditioning and discharging of the housing residues. The selective collection and recycling must be prioritized for the proper management of the solid residues of the city to occur. Educative environmental programs covering the different levels of the society are a necessity. Additionally, such programs are important for the proper sustainable development of the city and also to improve the quality of life of the population.

Keywords: urban contamination, environmental management, trash, recycling. 


\section{Introdução}

O município de Pelotas é a terceira cidade mais populosa do estado do Rio Grande do Sul, com 328.275 habitantes em uma área de 1.610,084 km² (IBGE, 2014). A gestão dos resíduos sólidos da cidade, considerando o conceito mais amplo disposto na Lei 12.305/2010 (BRASIL, 2015), é de responsabilidade da Secretaria de Obras e Serviços Urbanos (SOSU), enquanto que o gerenciamento dos resíduos, que compreende a coleta, o tratamento, o transbordo e a disposição final, está a cargo da Autarquia de Serviço Autônomo de Saneamento de Pelotas (SANEP) (PMGIRS, 2014). Kirchner et al. (2013) ressaltam que em 79\% dos municípios do Rio Grande do Sul, o serviço de manejo dos resíduos sólidos é realizado pelas prefeituras. Mattos et al. (2013) realizaram uma análise sistêmica do gerenciamento dos resíduos sólidos na zona sul do Rio Grande do Sul e constataram que a coleta dos resíduos nos municípios de Piratini, Arroio do Padre, Jaguarão, Turuçu e Pedro Osório é de responsabilidade da prefeitura.

Os resíduos sólidos gerados na cidade de Pelotas têm sua origem em residências, em estabelecimentos industriais e nos serviços de saúde. Além desses, são coletados também os resíduos domiciliar rural, o seletivo, o de container, entulhos e outros resíduos, sendo respectivamente da ordem de $31,7 \%, 14,7 \%, 0,1 \%, 0,7 \%, 1 \%, 14,4 \%$ e $37,4 \%$ de um total de $332.235 \mathrm{~kg} /$ dia (PMGIRS, 2014).

O Plano Municipal de Gestão Integrada de Resíduos Sólidos da Prefeitura Municipal de Pelotas (PMP) mostra que o serviço de coleta seletiva, implementado em 2010, é realizado em 18 zonas do município, equivalendo a $65 \%$ da área urbana (PMGIRS, 2014). Portanto, grande parte dos recicláveis gerados no município não sofre segregação, sendo disposto no aterro, onde são misturados ao lixo comum. Godecke e Walerko (2015) afirmam que a situação atual da coleta seletiva em Pelotas é deficiente em aspectos como a limitada frequência da coleta, a falta de regularidade de horários, a limitada área de abrangência do serviço e o pagamento de valor fixo ao terceirizado, independente da quantidade coletada. Caldeira et al (2009) salientam que normalmente uma parcela significativa da população não é atendida pela coleta seletiva.

Outro aspecto importante é o aterro sanitário "Colina do Sol", que foi desativado pela Fundação Estadual de Proteção Ambiental (FEPAM) em 2012, por estar localizado dentro do perímetro urbano na área central da cidade e ainda, pela proximidade com a Barragem Santa Bárbara, que é um dos locais responsáveis pelo abastecimento de água da cidade. Zanini e Lessa (2013) salientam que o lixo descartado pelo município de Pelotas é enviado ao aterro sanitário particular da cidade de Candiota/RS, localizado a $150 \mathrm{~km}$ de Pelotas. Foi projetado para receber resíduos de 20 municípios da região sul do Estado, com uma vida útil estimada em 24 anos.

O manejo dos resíduos sólidos produzidos nas áreas urbanas é considerado um dos grandes desafios enfrentados hoje pelas administrações públicas das cidades brasileiras. O ambiente urbano é um dos principais locais responsáveis por sofrer impactos ambientais devido à elevada quantidade de resíduos sólidos gerados pela população. As atividades cotidianas condicionam o morador urbano a observar determinados fragmentos do ambiente e não perceber situações de graves impactos ambientais. Mucelin e Bellini (2008) ressaltam que casos de agressões ambientais como poluição visual e disposição inadequada de lixo refletem hábitos cotidianos em que o observador é compelido a conceber como normais.

Desta forma, objetivou-se demonstrar os impactos ambientais dos resíduos sólidos no município de Pelotas através de fotografias.

\section{Material e métodos}

O trabalho foi realizado entre os meses de abril e junho de 2015, no município de Pelotas, situado no extremo sul do Rio Grande do Sul. A cidade é dividida em seis regionais, denominadas de Três Vendas, Laranjal, Centro, Areal, Porto e Fragata.

A pesquisa caracteriza-se como um estudo de caso, tendo como base a percepção ambiental através do dispositivo do olhar dos investigadores sobre os impactos ambientais dos resíduos sólidos nas regionais do Fragata, Centro e Porto. Mucelin e Bellini (2008) afirmam que a leitura perceptiva do ambiente urbano, tanto individual quanto coletiva, é produzida nas inter-relações fenomenológicas 
habituais entre morador e o ambiente. Os autores acrescentam ainda que o julgamento perceptivo do ambiente ocorre pela semiose dos signos locais experienciados, estabelecidos a partir dos constituintes do ambiente, que está intrinsecamente vinculado às crenças e hábitos vigentes, que conformam o uso.

Foram realizadas saídas de campo e observações in loco, com auxilio de câmeras digitais Canon Rebel $\mathrm{t} 2 \mathrm{i}^{\circledast}$ e Nikkon Coolpix L810 ${ }^{\circledR}$. Contemplar fragmentos de regiões do ambiente urbano permite observar a paisagem que retrata hábitos edificados temporal e culturalmente (MUCELIN; BELLINI, 2008). As imagens fotográficas foram compiladas para posterior análise.

\section{Resultados e discussão}

No município de Pelotas, pode-se observar que a deposição inadequada de equipamentos elétricos próximos a residências e pontos comerciais da Avenida Duque de Caxias, na regional do Fragata (Figura 1A), bem como os resíduos sólidos depositados em terrenos, nas regionais do Porto (Figura 1B) e do Fragata (Figura 1C), parecem ser uma prática comum por parte da população. Silva et al. (2013) estudando os impactos ambientais da destinação inadequada de resíduos sólidos urbanos na cidade de Ipameri/GO verificaram depósitos em terrenos baldios e margens de estrada. As formações de pequenos lixões causam contaminação do solo e da água superficial e subterrânea, dispersão de plásticos e outros materiais por ação do vento e intempéries, proliferação de insetos e outros vetores que afetam a saúde humana e também produz um impacto visual negativo com a conseqüente desvalorização de terras e propriedades vizinhas (MATTOS et al., 2013).

A)

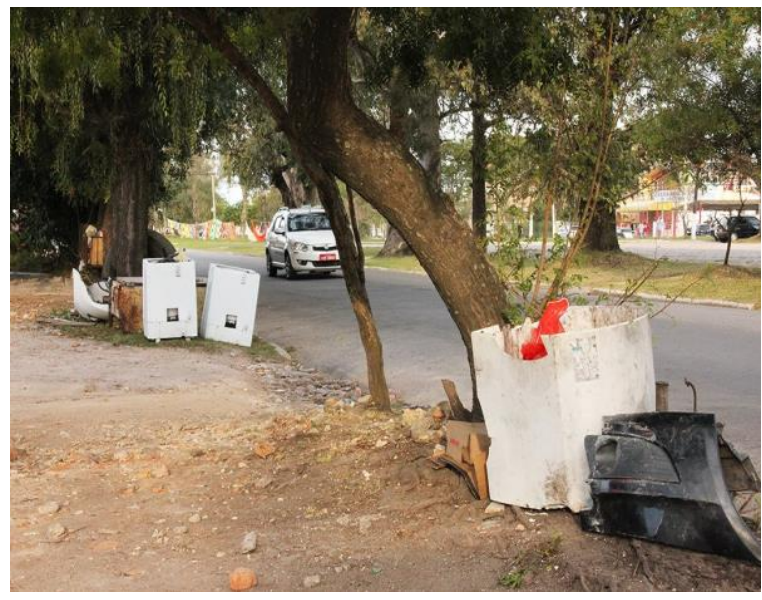

C)

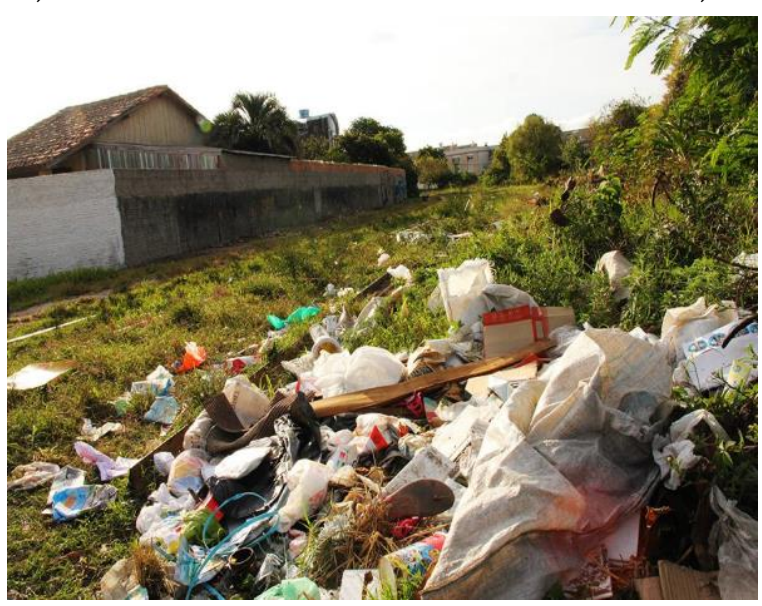

B)
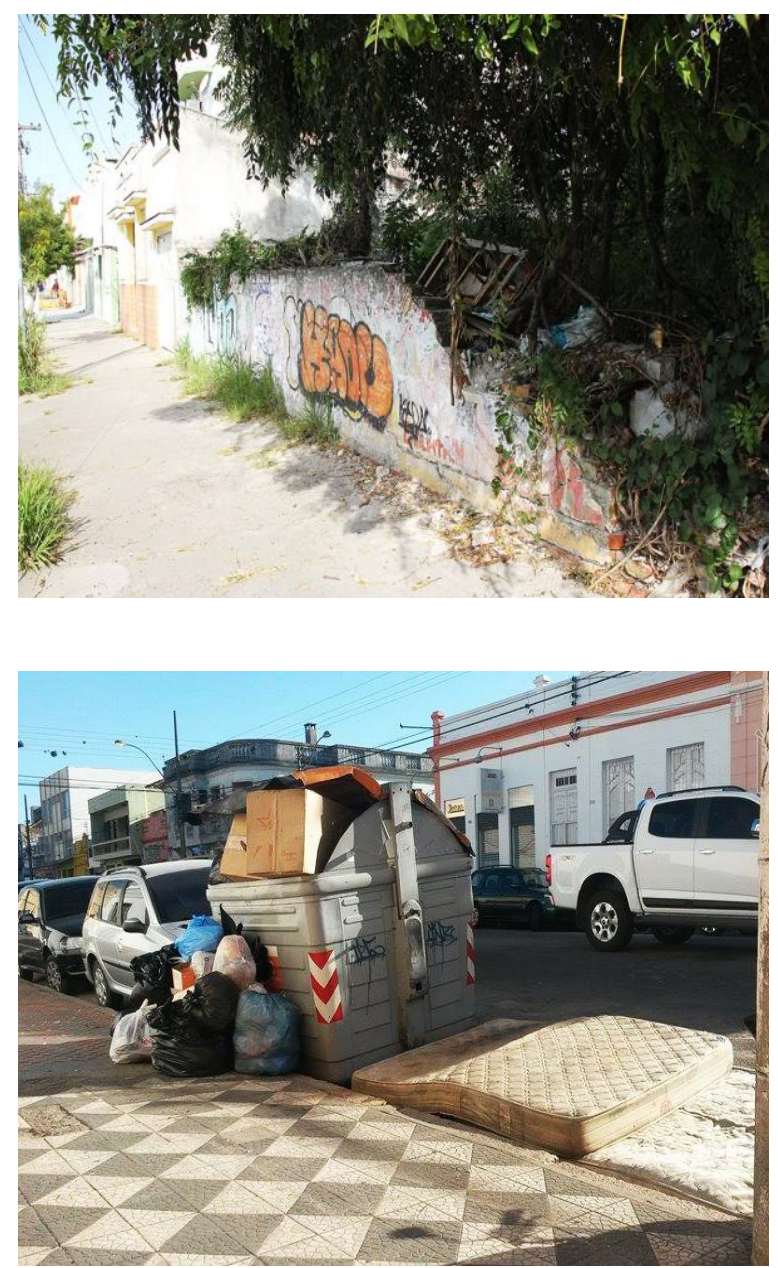

Figura 1. Deposição inadequada de equipamentos elétricos na Avenida Duque de Caxias na regional do Fragata (A), resíduos sólidos depositados em terrenos particulares na regional do Porto (B), resíduos sólidos de composição variada descartados na regional do Fragata (C) e descarte de resíduos domiciliares na regional do Centro (D) . Fonte: Acervo dos autores (2015) 
A problemática dos resíduos sólidos fica mais evidente na Figura 1D, que mesmo havendo a presença de coleta conteinerizada automatizada no local, os resíduos são dispostos de forma inadequada, o que demonstra a ausência de comprometimento por parte da população com a segregação, acondicionamento e destinação correta. Kemerich et al. (2013) investigaram a visão da população sobre a gestão de resíduos sólidos no município de Frederico Westphalen e constataram ineficiência na coleta e nas formas de disposição dos resíduos. Zanini e Lessa (2013) afirmam que uma maneira de tentar modificar essa questão seria a de intensificar a educação ambiental no município. Hempe e Noguera (2012) ressaltam que é importante que o gestor municipal, juntamente com as demais secretarias, elabore projetos com ações integradas e o envolvimento de todos, para que as temáticas, educação ambiental e resíduos sólidos sejam abordadas durante todo o ano, fazendo com que os colaboradores se tornem disseminadores de práticas ambientais.

Outro aspecto a ser considerado é o número insuficiente de coletores para abrigar o maior volume de resíduos produzidos na cidade. A geração de resíduos sólidos é proporcional ao aumento da população e desproporcional à disponibilidade de soluções para o gerenciamento dos rejeitos, resultando na redução do percentual da malha urbana atendida pelo serviço de coleta e o seu abandono em locais inadequados (ISAIA et al., 1999). Decorridos dois anos do estudo de Zanini e Lessa (2013), ainda pode-se verificar uma cultura negativa com relação disposição dos resíduos ou até mesmo na questão do consumo, o que demonstra a falta de conscientização por parte da população pelotense. Isso é reflexo do modelo de desenvolvimento econômico brasileiro que permite um maior consumo de produtos por parte da população. Aliado a isso, as indústrias produzem cada vez mais utensílios de curta duração, o que gera um aumento dos rejeitos no meio ambiente. Campos (2012) ressalta que o modelo de desenvolvimento praticado no Brasil caminha no sentido de atingir os patamares registrados pelos países desenvolvidos. Godecke et al. (2012) explicam que o consumismo inconsciente gera um maior volume de resíduos, provocando uma redução da capacidade ambiental para a prestação dos serviços ecossistêmicos, o que acaba reduzindo o bem estar social devido as doenças, extremos climáticos, perdas na produção de alimentos e disponibilidade de água.

Nas regionais do Fragata (Figura 2A) e do Porto (Figura 2B), a situação agrava-se ainda mais pela queima de resíduos sólidos de composição variada. A queima do lixo dissemina no ar vários produtos tóxicos, que variam da fuligem às cancerígenas dioxinas, resultantes da queima de plásticos. Os impactos decorrentes dos gases emitidos pela combustão de biomassa afetam um número significativo de pessoas, sobretudo em países em desenvolvimento (RIBEIRO; ASSUNÇÃO, 2002).

A)

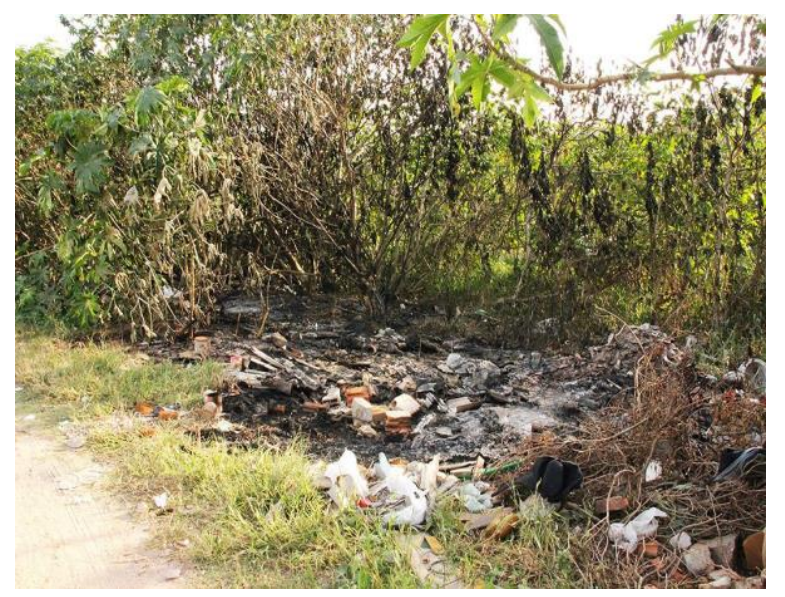

B)

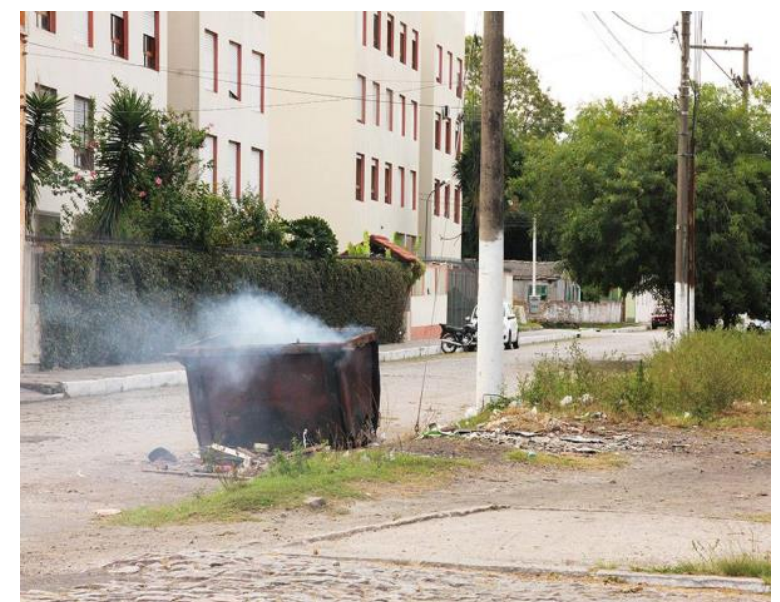

Figura 2. Queima de resíduos sólidos nas regionais do Fragata (A) e do Porto (B)

Fonte: Acervo dos autores (2015)

No que diz respeito aos recursos hídricos no município, as imagens mostram o descarte de resíduos sólidos na margem do Arroio Pepino (Figura 3A) e também a contenção do acúmulo de lixo 
na parte final do arroio, situado na regional do Porto (Figura 3B). É importante salientar que o Arroio Pepino percorre as regionais do Areal, Centro, Três Vendas e Porto, desaguando no Canal São Gonçalo, que faz ligação entre a Lagoa Mirin e Laguna dos Patos, envolvendo um extenso ecossistema, onde estão presentes espécies nativas da flora e fauna da região. Em decorrência disso, os efeitos negativos decorrentes da prática de disposição inadequada de resíduos sólidos torna-se ainda mais grave, atingindo o Canal São Gonçalo, que é uma importante fonte de abastecimento de água para o município de Pelotas. Mucelin e Bellini (2008) afirmam que essas práticas habituais podem provocar a contaminação dos corpos d'água, assoreamento, proliferação de vetores transmissores de doenças, poluição visual, mau cheiro e contaminação do ambiente e enchentes.

A)

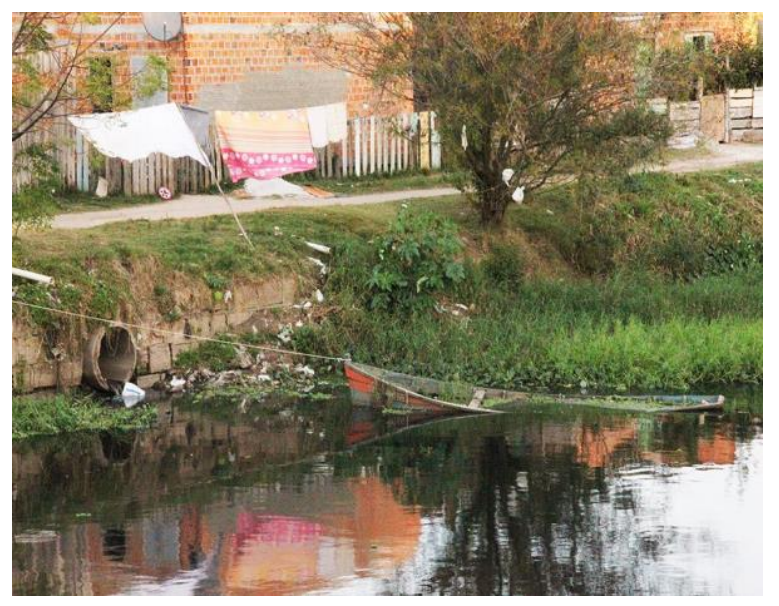

B)

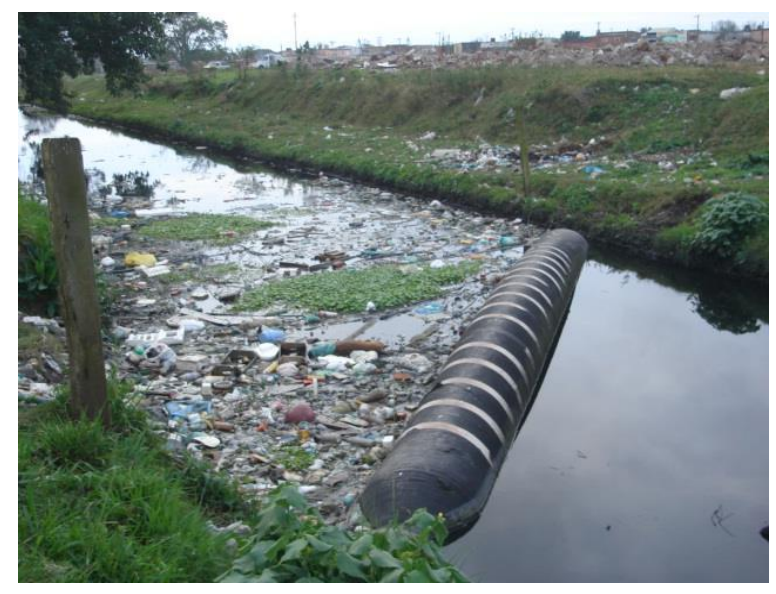

Figura 3. Descarte de resíduos sólidos na margem do Arroio Pepino (A) e contenção do acúmulo de resíduos sólidos no Arroio Pepino que desemboca no Canal São Gonçalo na regional Porto (B)

Fonte: Acervo dos autores (2015)

A falta de conscientização da população quanto á segregação, acondicionamento e disposição correta dos resíduos fazem com que animais convivam diariamente em ambientes que gradativamente tornam-se verdadeiros lixões próximos a residências (Figura 4). Essa proximidade com o lixo predispõe os animais e o homem a contraírem doenças como a salmonelose, toxoplasmose, leptospirose, cólera, disenteria, cisticercose e giardíase. Aliado a isso, a falta de uma gestão eficiente dos resíduos sólidos urbanos colabora para a degradação ambiental no município de Pelotas. Da mesma forma, Gomes et al. (2012) constataram na cidade de Passo Fundo/RS a falta de capacitação técnica administrativa pública municipal, a ausência de políticas públicas voltadas aos resíduos sólidos e a falta de conscientização da população, que não faz separação de recicláveis na fonte. Zanini e Lessa (2013) afirmam que na cidade de Pelotas não existe uma cultura positiva com relação aos resíduos sólidos, seja na separação e até mesmo na questão de consumo, pelo fato de não existir a mínima conscientização do que está sendo gerado. 


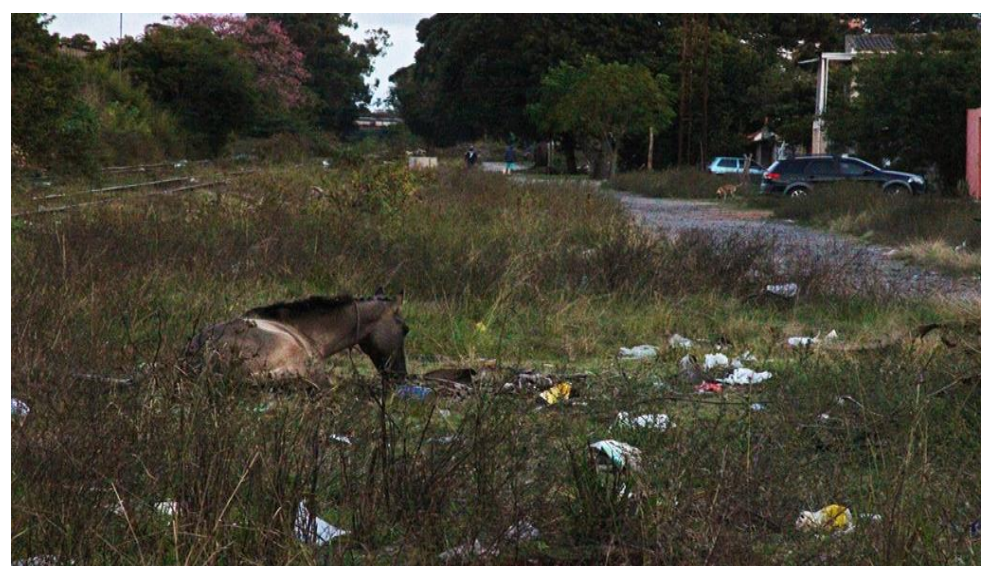

Figura 4. Animal em estado enfermo na regional do Fragata Fonte: Acervo dos autores (2015)

O acúmulo de garrafas de refrigerante, embalagens e outros tipos de resíduos acarretam a obstrução das tubulações (Figura 5A), dificultando a drenagem das águas em épocas de chuva intensa, colaborando para as enchentes na Avenida Bento Gonçalves, localizada na regional Centro (Figura 5B). Mancini et al. (1998) comentam que os plásticos, devido a sua pouca degradabilidade, permanecem na natureza por longos períodos, causando a poluição visual e química do ambiente. Teixeira (2010) explica que a produção de resíduos cresce proporcionalmente à urbanização. O aumento do volume de resíduos gerados está associado aos hábitos modernos de consumo excessivo, a grande disponibilidade de produtos industrializados acondicionados em embalagens e a redução da vida útil dos produtos (NEVES; CASTRO, 2012). Silva et al. (2013) ressaltam que a coleta seletiva e a reciclagem se constituem em medidas mitigatórias, contribuindo para a redução do impacto ambiental causada pelo descarte inadequado de embalagens. Nesse sentido, Godecke e Walerko (2015) constataram que no município de Pelotas se faz necessária a ampliação do convênio com as cooperativas de recicladores, a coleta individual dos recicláveis e a educação ambiental, no intuito de elevar o nível de adesão à segregação e a correta destinação dos recicláveis nos domicílios.
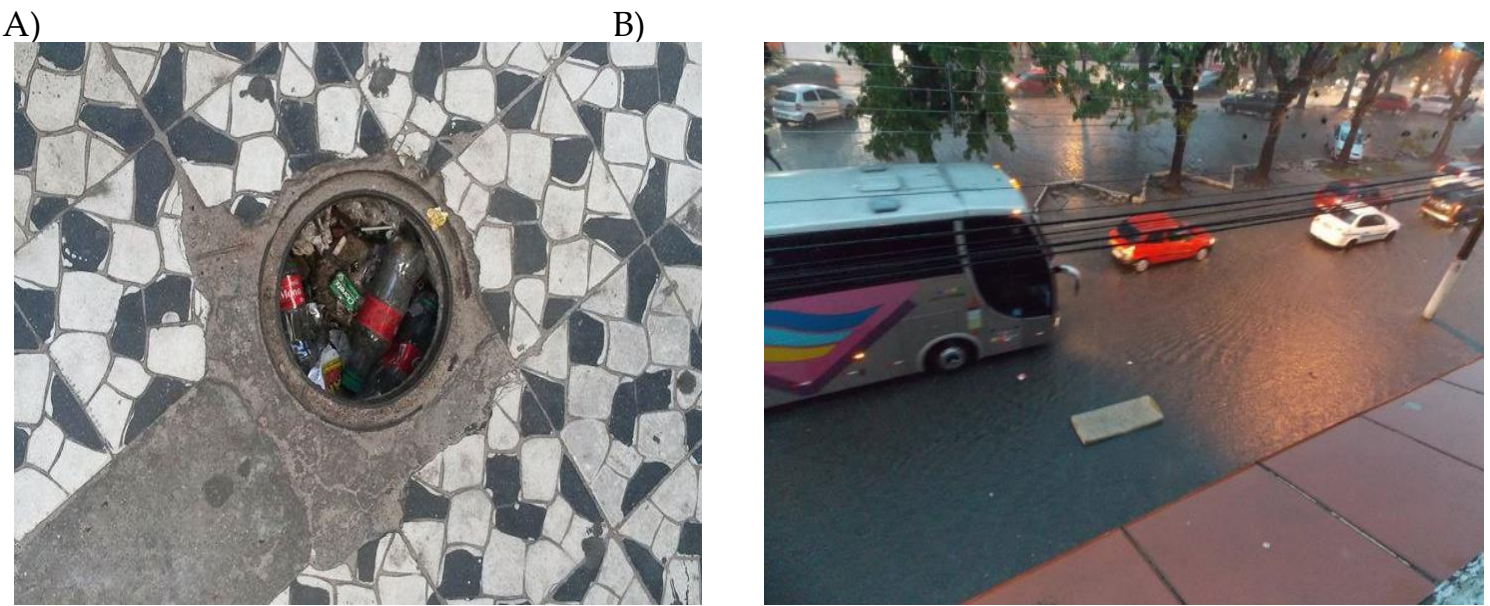

Figura 5. Obstrução de tubulações pelo acúmulo de resíduos sólidos na regional Centro (A) e enchente na Avenida Bento Gonçalves na regional Centro (B)

Fonte: Acervo dos autores (2015) 


\section{Conclusões} Pelotas.

A disposição inadequada dos resíduos sólidos causa impactos ambientais no município de

O gerenciamento dos resíduos sólidos é ineficiente e deve ser melhorado.

A presença de resíduos sólidos em locais inapropriados acarreta problemas sociais, ambientais, econômicos e administrativos.

A população deve realizar a segregação, o acondicionamento e a disposição correta dos resíduos domiciliares.

A coleta seletiva e a reciclagem devem ser priorizadas para uma correta gestão dos resíduos sólidos da cidade.

São necessários programas de educação ambiental que contemplem os diferentes âmbitos da sociedade para que seja alcançado o desenvolvimento sustentável do município e a melhoria da qualidade de vida da população.

\section{Referências}

BRASIL, Lei n. 12.305 de 02 de agosto de 2010. Institui a Politica Nacional de Residuos Solidos; altera a Lei no 9.605, de 12 de fevereiro de 1998; e da outras providencias. Disponivel em $<$ http://www.planalto.gov.br/ccivil_03/_ato2007-2010/2010/lei/112305.htm>. Acesso em 20 de julho de 2015.

CALDEIRA, M.M.; REZENDE, S.; HELLER, L. Estudo dos determinantes da coleta de resíduos sólidos urbanos em Minas Gerais. Engenharia Sanitária e Ambiental, v. 14, n. 3, p. 391-400, 2009.

CAMPOS, H.K.T. Renda e evolução na geração per capita de resíduos sólidos no Brasil. Engenharia Sanitária e Ambiental, v. 17, n. 2, p. 171-180, 2012.

GODECKE, M.V.; NAIME, R.H.; FIGUEIREDO, J.A.S. O consumismo e a geração de resíduos sólidos urbanos no Brasil. Revista Eletrônica em Gestão, Educação e Tecnologia Ambiental, v. 8, n. 8, p. 1700-1712, 2012.

GODECKE, M.V.; WALERKO, W.S. Gestão de resíduos sólidos urbanos: Estudo do caso da reciclagem em Pelotas, RS. Revista Eletrônica em Gestão, Educação e Tecnologia Ambiental, v. 19, n. 2, p. 359373, 2015.

GOMES, A.P.; PANDOLFO, A.; PASSINI, A.F.C.; PRIETTO, P.D.M.; PORTELA, N.B. Diagnóstico do sistema de gerenciamento dos resíduos sólidos urbanos do município de Passo Fundo/RS. Revista DAE, n. 190, p. 44-55, 2012.

HEMPE, C.; NOGUERA, T.O.C. A educação ambiental e os resíduos sólidos urbanos. Revista Eletrônica em Gestão, Educação e Tecnologia Ambiental, v. 5, n. 5, p. 682-695, 2012.

INSTITUTO BRASILEIRO DE GEOGRAFIA E ESTATÍSTICA (IBGE). Cidades. Disponível em: $<$ http://www.ibge.gov.br/cidadesat/index.php>. Acesso em: 02 ago. 2014.

ISAIA, E.B.I.; ISAIA, T.; ROTH, B.W. Destinação final dos resíduos sólidos urbanos. Ciência e Ambiente, v. 1, n. 18, p. 25-40, 1999.

KEMERRICH, P.D.DA C.; RODRIGUES, A.C.; UCKER, F.E.; RENZ, D.; HAAS, A. Gestão dos resíduos sólidos urbanos: A visão da população na cidade de Frederico Westphalen. Revista Eletrônica em Gestão, Educação e Tecnologia Ambiental, v. 10, n. 10, p. 2059-2068, 2013. 
KIRCHENER, R.M.; SILINSKE, J.; BENETTI, J.K.; CHAVES, M.A.DE.; SCHERER, M.E.; SAIDELLES, A.P.F.; ESSI, L. Manejo de resíduos sólidos na região sul do Brasil. Revista Eletrônica em Gestão, Educação e Tecnologia Ambiental, v. 14, n. 14, p. 2846-2854, 2013.

MANCINI, S.D.; BEZERRA, M.N.; ZANIN, M. Reciclagem de PET advindo de garrafas de refrigerante pós-consumo. Polímeros: Ciência e Tecnologia, v. 8, p. 68-75, 1998.

MATTOS, P.H.; ANELLO, L.F.S.; TAGLIANI, C.R.A. Uma análise sistêmica do gerenciamento dos resíduos sólidos em nove municípios da zona sul do Rio Grande do Sul. Diálogos \& Ciência, v. 33, p. 45-49, 2013.

MUCELIN, C.A.; BELLINI, M. Lixo e impactos ambientais perceptíveis no ecossistema urbano. Sociedade \& Natureza, v. 20, n. 1, p. 111-124, 2008.

NEVES, A.C.R.R.; CASTRO, L.O.DE.A. Separação de materiais recicláveis: panorama no Brasil e incentivos à prática. Revista Eletrônica em Gestão, Educação e Tecnologia Ambiental, v. 8, n. 8, p. 1734-1742, 2012.

PREFEITURA NUNICIPAL DE PELOTAS. Plano Municipal de Gestão Integrada de Resíduos Sólidos (PMGIRS) - Município de Pelotas/RS. 2014. 194p.

RIBEIRO, H.; ASSUNÇÃO, J.V.DE. Efeitos das queimadas na saúde humana. Estudos Avançados, v. 16, n. 44, p. 125-148, 2002.

SILVA, C. O.; SANTOS, G. M.; SILVA, L. N. A degradação ambiental causada pelo descarte inadequado das embalagens plásticas: estudo de caso. Revista Eletrônica em Gestão, Educação e Tecnologia Ambiental, v. 13, n. 13, p. 2683-2689, 2013.

SILVA, M.C.DA.C.; PELÁ, A.; BARRETOS, F.R.DE.M. Impactos ambientais na destinação inadequada de resíduos sólidos urbanos na cidade de Ipameri-GO: um estudo de caso. Revista Eletrônica em Gestão, Educação e Tecnologia Ambiental, v. 17, n. 17, p. 3230-3239, 2013.

TEIXEIRA, C. A. G. Jogando Limpo: estudo das destinações finais dos resíduos finais dos resíduos sólidos da construção civil no contexto urbano de Montes Claros. Montes Claros, Dissertação (Mestrado em Desenvolvimento Sustentável) - Universidade Estadual de Montes Claros, 2010.

ZANINI, S. R. D.; LESSA, V. N. Gestão de resíduos sólidos: o resíduo urbano e sua alocação no município de Pelotas. Revista Eletrônica Academicus, v. 1, n. 1, p. 25-42, 2013. 